\title{
The Site for Initiation of Action Potential Discharge over the Somatodendritic Axis of Rat Hippocampal CA1 Pyramidal Neurons
}

\author{
Ray W. Turner, ${ }^{1,2}$ Donald E. R. Meyers, ${ }^{2, a}$ Thomas L. Richardson, ${ }^{1, b}$ and Jeffery L. Barker ${ }^{2}$ \\ 'Department of Physiology, University of British Columbia, Vancouver, British Columbia, Canada V6T 1W5 and \\ 2Laboratory of Neurophysiology, National Institutes of Health, NINCDS, Bethesda, Maryland 20892
}

Early electrophysiological studies in the mammalian hippocampus reported that orthodromic depolarization of pyramidal cells evoked action potential discharge (presumed $\mathrm{Na}^{+}$dependent) both at the axon hillock and at one or more sites in the dendritic arborization (Cragg and Hamlyn, 1955; Andersen, 1959, 1960; Spencer and Kandel, 1961; Andersen and Lomo, 1966). Although tetrodotoxin (TTX)-sensitive spikes have been recorded at the dendritic level (Wong et al., 1979; Benardo et al., 1982; Miyakawa and Kato, 1986; Turner et al., 1989), the site for initiation of these potentials has not yet been determined. In this study, we examine the site for initiation of $\mathrm{Na}^{+}$spike discharge over the cell axis of rat hippocampal CA1 pyramidal neurons.

Intrasomatic and intradendritic recordings were obtained from pyramidal neurons of hippocampal slices maintained in vitro. Spike discharge was evoked by alvear (antidromic) stimulation or orthodromically by stimulation of afferent inputs in stratum oriens (SO) or stratum radiatum (SR). Antidromic and orthodromic spikes were greatest in amplitude in somatic recordings and declined over the apical dendritic axis, while spike half-width was shortest at the cell body and increased with distance from stratum pyramidale. Measurements of orthodromic spike threshold revealed that the only location at which spikes discharged at a consistent membrane potential at threshold intensity (voltage threshoid) was the cell body region. Finally, at threshold intensity, SR-evoked intradendritic spikes were blocked by local application of TTX in stratum pyramidale, while spike blockade at suprathreshold intensity required the diffusion of TTX into the apical dendritic region.

These results indicate that, for threshold intensities of stimulation, antidromic and orthodromic spike discharge in

Received June 4, 1990; revised Feb. 19, 1991; accepted Feb. 27, 1991.

This research was supported by a Canada Medical Research Council (MRC) grant to J. J. Miller and by an NIH grant to J.L.B. R.W.T. was supported by a Canada MRC Studentship and Postdoctoral Fellowship, T.L.R. by the British Columbia Health Care Foundation, and D.E.R.M. by an NIH Fogarty Fellowship to the Laboratory of Neural Control, NIH, MD. R.W.T. and T.L.R. wish to thank Dr. J. J. Miller for supervisory support during the initial phase of these experiments. Dr. J. Sarvey and Dr. R. E. Burke are thanked for the use of a Burleigh Inchworm and electrometer, and L. Maler for helpful comments on the manuscript.

Correspondence should be addressed to R. W. Turner, Department of Physiology, Neuroscience Research Group, University of Calgary, 3330 Hospital Drive N.W., Calgary, Alberta, Canada T2N 4N1.

Present address: Bekesy Laboratory of Neurobiology, 1993 East-West Road, University of Hawaii, Honolulu, HI 96822.

b Present address: School of Kinesiology, Simon Fraser University, Burnaby, British Columbia, Canada V5A IS6.

Copyright (C) 1991 Society for Neuroscience $0270-6474 / 91 / 112270-11 \$ 03.00 / 0$
CA1 pyramidal cells is initiated in the region of the cell body layer, subsequently conducting over the apical dendrites in a retrograde fashion. In contrast, SR-evoked orthodromic spike discharge exhibits an intensity-dependent shift in the site of origin up to $200 \mu \mathrm{m}$ within the apical dendritic arborization.

Synaptic activation of central neurons results in action potential discharge when the summation of excitatory and inhibitory synaptic potentials exceeds the voltage for activating regenerative $\mathrm{Na}^{+}$and/or $\mathrm{Ca}^{2+}$ conductances. Traditionally, a high density of these channels was believed to exist only in the region of the axon hillock or initial segment, ensuring a low voltage threshold for the initiation of action potential discharge (Coombs et al., 1957; Tauc, 1962; Funch and Faber, 1982; Wollner and Catterall, 1986). This view, however, has been substantially altered with the demonstration that dendritic membrane also exhibits voltage-dependent properties (Jeffereys, 1979; Wong et al., 1979; Llinas and Sugimori, 1980; Benardo et al., 1982; Masukawa and Prince, 1984; Faber and Korn, 1986; Miles and Wong, 1986; Huguenard et al., 1989). The role of dendritic ion channels in the generation of action potential discharge has long been a focus of work in the mammalian hippocampus. This phenomenon has been most clearly established for the case of $\mathrm{Ca}^{2+}$ channels, where orthodromic depolarization under conditions of reduced inhibitory function can generate long-duration allor-none responses in pyramidal cells (Wong and Prince, 1979; Wong et al., 1979; Schwartzkroin and Prince, 1980; Masukawa and Prince, 1984; Swann et al., 1986).

The generation of $\mathrm{Na}^{+}$spikes in dendritic regions of pyramidal cells has also been proposed on the basis of field potential, intrasomatic, and intradendritic recordings. At the field potential level, antidromic or orthodromic stimulation has been shown to evoke a short-duration, tetrodotoxin (TTX)-sensitive, negative field potential that conducts over the somatodendritic axis (Cragg and Hamlyn, 1955; Andersen, 1959, 1960; Fujita and Sakata, 1962; Andersen and Lomo, 1966; Sperti et al., 1967; Leung, 1979; Miyakawa and Kato, 1986; Richardson et al., 1987; Taube and Schwartzkroin, 1988b; Turner et al., 1989). Intradendritic recordings also show that depolarizing current injection evokes action potential discharge that can be recorded at the apical dendritic level (Wong et al., 1979; Benardo et al., 1982; Masukawa and Prince, 1984). Fast spikes in these recordings are blocked by bath-applied TTX (Wong et al., 1979) or intracellularly injected QX-314 (Benardo et al., 1982). While the occurrence of $\mathrm{Na}^{+}$spike discharge in dendritic regions appears to be well established, the site for initiation of these potentials (axon hillock vs. dendritic) has been more difficult to 
establish (Cragg and Hamlyn, 1955; Andersen, 1959; Andersen and Lomo, 1966; Miyakawa and Kato, 1986; Richardson et al., 1987; Turner et al., 1989; Herreras, 1990).

Spencer and Kandel (1961) proposed the only existing model for dendritic spike generation in pyramidal cells, where synaptic depolarization leads to the initial activation of a spike from local regions of dendritic membrane ("hot spots") exhibiting a low threshold for action potential discharge. Active spike conduction was believed to fail within the dendritic tree, leading to an electrotonic conduction of the spike that gave rise to a fast prepotential (FPP) evident in somatic recordings. The generation of dendritic $\mathrm{Na}^{+}$spikes prior to that at the axon hillock is supported by the presence of a stratum radiatum (SR)-evoked (TTX-sensitive) extracellular population discharge and current sink in proximal stratum radiatum that contributes to generation of the cell body population spike (Cragg and Hamlyn, 1955; Andersen, 1959; Andersen and Lomo, 1966; Turner et al., 1989; Herreras, 1990). Nevertheless, several key elements of Spencer and Kandel's (1961) model have not been fully tested, including the site(s) for spike initiation, the direction of spike conduction (somatic vs. dendritic), the mechanism for spike conduction (passive vs. active), or the identity of FPPs (MacVicar and Dudek, 1981).

The present study therefore examined the site for initiation of both antidromic and orthodromic spike discharge in CA1 pyramidal cell somata and apical dendrites evoked at threshold intensities of stimulation. Particular attention was paid to the origin of SR-evoked spike discharge evoked at both threshold and suprathreshold stimulus intensities.

Some of this work has been presented in abstract form (Turner et al., 1987, 1988).

\section{Materials and Methods}

Slice preparation. Intra- and extracellular recordings of pyramidal cells were obtained in the $\mathrm{CA} 1 \mathrm{~b}$ region of mid-dorsal rat hippocampal slices in vitro using procedures detailed in Turner et al. (1989). Briefly, hippocampi were dissected out in cold $\left(4^{\circ} \mathrm{C}\right)$ preoxygenated Ringer's solution consisting of (in mM) $124 \mathrm{NaCl}, 3 \mathrm{KCl}, 0.75 \mathrm{KH}_{2} \mathrm{PO}_{4}, 1.6 \mathrm{CaCl}_{2}$, 1.2 $\mathrm{MgSO}_{1}, 24 \mathrm{NaHCO}_{3}$, and 10 D-glucose. Slices of $400 \mu \mathrm{m}$ thickness were maintained as an "interface" preparation at a temperature of 34.5 $\pm 0.5^{\circ} \mathrm{C}$ and superfused with $95 \% \mathrm{O}_{2}, 5 \% \mathrm{CO}_{2}$.

Stimulating and recording procedures. Bipolar stimulating electrodes consisted of twisted $62 \mu \mathrm{m}$ nichrome wire, with square wave pulses $(0.1$ msec, $1-50 \mathrm{~V}$ ) delivered through isolation units (Digitimer SIU). Glass microelectrodes for intracellular recording were short-shanked electrodes $(1.5 \mathrm{~mm}$ o.d.) backfilled with $1 \mathrm{M}$ potassium acetate for a final resistance of 50-100 M 2 . Extracellular recording electrodes were broken back under microscopic control (1-2 $\mu \mathrm{m}$ tip diameter) and backfilled with $1 \mathrm{M} \mathrm{NaCl}(1-5 \mathrm{M} \Omega$ ) or HEPES (10 mM; $N$-2-hydroxyethanepiperizine- $N$ '-2-ethane sulphonic acid)-buffered Ringer's solution (10-30 M $\Omega$ ) consisting of (in mM) $148 \mathrm{NaCl}, 3.75 \mathrm{KCl}, 1.6 \mathrm{CaCl}_{2}, 1.2 \mathrm{MgCl}_{2}, 10$ D-glucose; $\mathrm{pH} 7.4,310 \mathrm{mmol} / \mathrm{kg}$. All electrical activity was either referenced to an $\mathrm{Ag} / \mathrm{AgCl}$ bath ground (DC, $10-\mathrm{kHz}$ band pass), displayed on a storage oscilloscope and photographed, or led to a PDP $11 / 23$ or Compaq 386 computer for storage and subsequent analysis. Threshold stimulus intensity was defined as the intensity that evoked spike discharge on approximately $50 \%$ of stimulus trials or, in a few cases, when set just above the point of failure for spike discharge. High or suprathreshold intensities were defined as two to three times the intracellular spike threshold or the intensity required to evoke $\geq 3-4 \mathrm{mV}$ cell body population spike.

Intracellular recordings. Intracellular recordings were taken from single impalements at the somatic or dendritic level and were not obtained from dual impalements of a single pyramidal neuron. Resting input resistance was taken as the slope of the best-fit line over the linear range of a voltage/current plot, while resting potential was obtained upon withdrawing the electrode to the extracellular compartment. Membrane characteristics defined as satisfactory were resting potentials of at least
$-57 \mathrm{mV}$ and input resistance of $18 \mathrm{M} \Omega$ or more (range, 18-50 M $\Omega$ ). Although input resistance was assessed for each impalement, this valuc was not documented in some early recordings and therefore could not be included in graphs of input resistance (see Figs. 3,4). Action potential amplitude and half-width as well as EPSP amplitudes were measured with respect to prestimulus baseline. Average values are expressed as mean \pm SEM.

Recording distance along the pyramidal cell axis was referenced to the border of stratum radiatum and stratum pyramidale (" 0 " $\mu \mathrm{m}$ ), visible under transillumination as a clear stratum containing the cell bodies of pyramidal cells. The distance of a recording site was measured by an eyepiece graticule and normalized to a value of $400 \mu \mathrm{m}$ (Fig. $1 A$ ), the average distance from stratum pyramidale to the hippocampal fissure (Richardson et al., 1987). Dendritic recording sites were then assigned to the nearest $30 \mu \mathrm{m}$ division point along this axis. In initial experiments, rccording distance was cstimated as a fraction of the distance to the hippocampal fissure by visually estimating the halfway point between the cell body layer and the fissure. This region was further subdivided into three equal distances, partitioning the total distance into sections approximating $65 \mu \mathrm{m}$. Impalements falling between $65 \mu \mathrm{m}$ divisions were given a value intermediate to the distance of adjacent division points. This technique proved to be a reasonably accurate method of judging the distance of a recording site, and initial estimates made in this way were found to be comparable to those obtained by measurement with a graticule. Recordings $\leq 150 \mu \mathrm{m}$ from stratum pyramidale are designated as "proximal" dendritic, while those $>150 \mu \mathrm{m}$ are from the "mid-distal" dendritic region.

Local pressure application of tetrodotoxin. Pressure application of TTX was accomplished by adding $10-40 \mu \mathrm{M}$ TTX to the modified Ringer's solution electrolyte of extracellular recording electrodes (above). These electrodes were positioned to a similar depth and in line with the axis of the cell population sampled by the intracellular recording electrode. The TTX-containing electrolyte was then ejected over restricted regions of the cell (and the immediate location of the extracellular recording site) by applying short pulses of air pressure to the side port of the electrode holder ( $70-300 \mathrm{msec}, 5-17$ psi; Turner et al., 1989). In this manner, spike discharge was blocked at a remote location from the intracellular recording site. Alternatively, repetitive pressure pulses (one per $2-5 \mathrm{sec}$ ) were used to promote the diffusion of TTX beyond the initial ejection site to more distal regions of the pyramidal cell structure. The consistency of results obtained with this technique indicates that the alignment of TTX electrodes was adequate to achieve this goal.

\section{Results}

\section{Intradendritic recordings}

Intracellular recordings of CA1 pyramidal neurons were obtained from 120 somatic (stratum pyramidale) and 161 apical dendritic impalements at locations up to $265 \mu \mathrm{m}$ within SR (Fig. 1 $A$ ). Intradendritic recordings were identified according to the characteristics of orthodromic dendritic potentials reported in previous investigations (Wong et al., 1979; Masukawa and Prince, 1984; Taube and Schwartzkroin, 1988a). Discharge patterns typical of nonpyramidal neurons (Schwartzkroin and Mathers, 1978; Ashwood et al., 1984; Lacaille and Schwartzkroin, 1988a,b) were very infrequently encountered. Intracellular injection of HRP ( $n=12)$ further confirmed that intracellular recordings in stratum radiatum corresponded to dendritic impalements of pyramidal cells. The neuron in Figure $1 B$ was injected with HRP at a recording site of $100 \mu \mathrm{m}$ from the border of stratum pyramidale (Fig. $1 B$, arrow). These cells had a structure characteristic of pyramidal neurons, with the soma in stratum pyramidale and a proximal apical dendritic shaft bifurcating a short distance within stratum radiatum. Action potential discharge recorded prior to injection of HRP is shown for antidromic (Fig. 1C) and SR stimulation (Fig. 1D). Evoked field potentials recorded immediately following withdrawal of the electrode (Fig. 1C,D) are characteristic of those recorded in stratum radiatum (Andersen, 1960; Sperti et al., 1967; Turner 
A

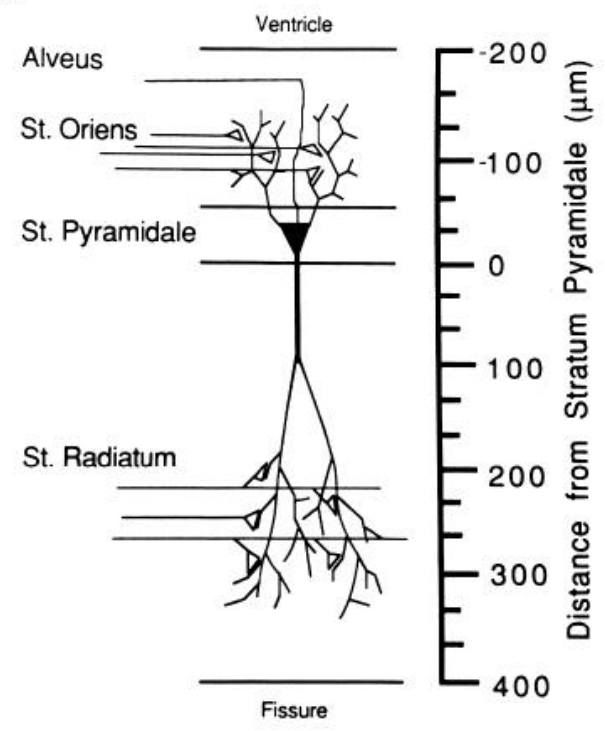

B

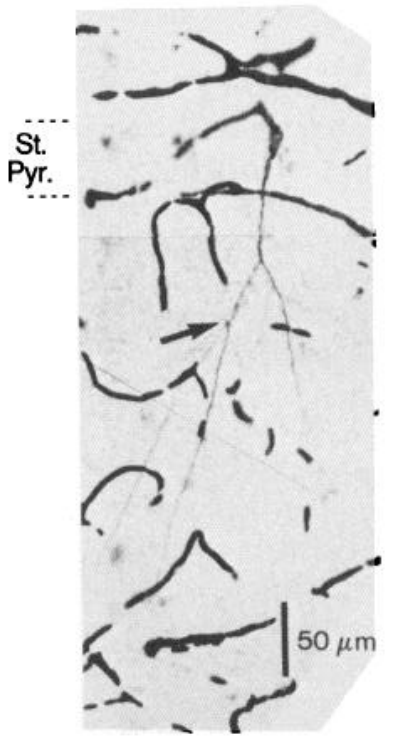

C

Stim. Site - Alveus

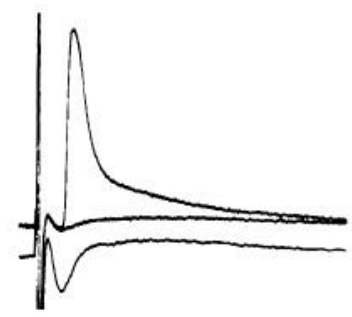

D

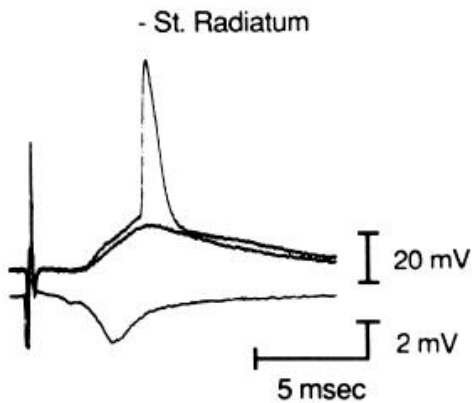

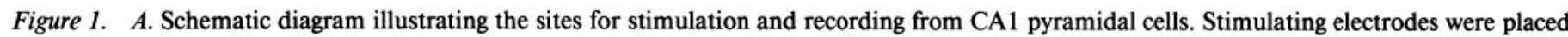

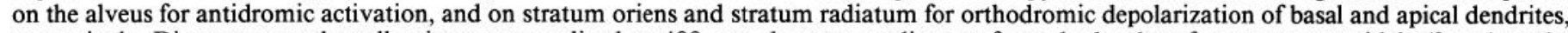

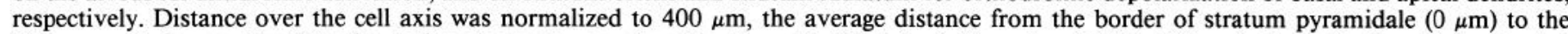

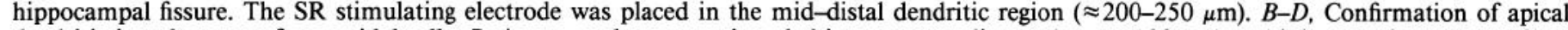

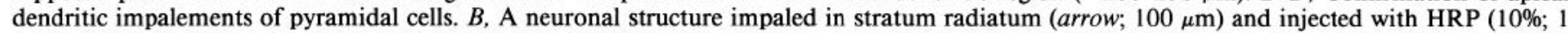

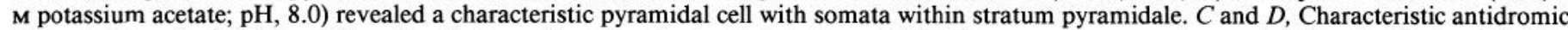

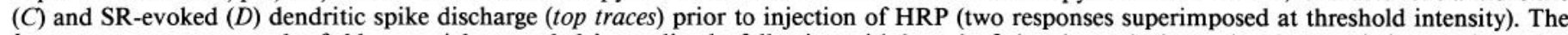

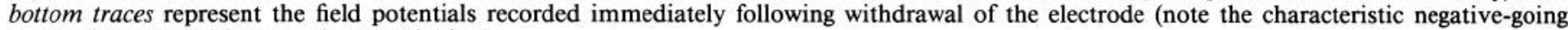
extracellular dendritic synaptic potential in $D$ ).

et al., 1989; Herreras, 1990), further verifying the placement of the intracellular electrode at the apical dendritic level of pyramidal cells.

Resting potential and input resistance for pyramidal cell impalements were comparable at the somatic and dendritic level. Our average value of resting membrane potential (samples chosen randomly) in somatic recordings was $64.4 \pm 0.6 \mathrm{mV}(n=$ $50)$ and $64.4 \pm 0.5 \mathrm{mV}$ in apical dendrites $(n=50)$. The average input resistance at the soma was $27.4 \pm 1.0 \mathrm{M} \Omega(n=50)$ and $28.5 \pm 1.2 \mathrm{M} \Omega$ in apical dendrites $(n=50)$. No progressive change in either of these parameters was detected with recording distance from stratum pyramidale (see Figs. 3, 4).

\section{Antidromic and orthodromic spike discharge at threshold stimulus intensities}

Our first investigations focused upon the site for initiation of action potential discharge near threshold for activation. In these studies, up to three stimulating electrodes were placed for stimulation of efferent pyramidal cell fibers in the alveus (antidromic) or orthodromic inputs in stratum oriens (SO) or SR (Fig. 1A). The SR-stimulating electrode was positioned approximately $200-250 \mu \mathrm{m}$ from stratum pyramidale to activate afferent inputs in the mid-distal apical dendritic region (Fig. 1). Antidromic spike discharge was thus compared to two forms of orthodromic stimulation, with data presented in the order of alveus, SO, and SR stimulation according to their respective degree of apical dendritic depolarization.

Representative examples of spike discharge evoked at threshold intensities in pyramidal cell somata and at various locations along the apical dendritic tree are shown in Figure 2. Alvear stimulation evoked single spike discharge in somata and apical dendrites up to $265 \mu \mathrm{m}$ from stratum pyramidale (Fig. $2 A$ ). These spikes arose directly from baseline with a short invariant latency; characteristics consistent with an antidromic spike invasion of the somatodendritic axis (Leung, 1979; Sperti et al., 1967; Richardson et al., 1987; Turner et al., 1989). SO stimulation and synaptic depolarization of pyramidal cell basal dendrites evoked a graded EPSP and single spike discharge that was recorded in both somata and apical dendrites (Fig. $2 B$ ). SOevoked EPSPs decreased in amplitude over the apical dendritic axis in a manner expected for a synaptic response generated in the basal dendritic arborization (Fig. $2 B$; see also Fig. $4 C$; Richardson et al., 1987; Turner and Richardson, 1991). In comparison, SR-evoked EPSPs were greatest in amplitude and rate of rise in more distal apical dendritic recordings (Fig. $2 C$; see also Fig. 4C).

\section{Antidromic and orthodromic spike amplitude and half-width}

Antidromic and orthodromic spikes clearly differed between somatic and dendritic recording sites (cf. Fig. 2, soma vs. 265 $\mu \mathrm{m}$ ). We therefore compared the amplitude and half-width (width at half amplitude) of spikes recorded at varying locations over the somatodendritic axis. The average amplitude of antidromic and orthodromic spikes are shown in Figure $3 A-C$. These measurements demonstrate that the amplitude of all evoked spikes was greatest in the cell body region, decreasing along the apical dendrite with recording distance from stratum pyramidale. The average values of spike half-width for those responses recorded on a suitable time base are shown in Figure $3 D-F$. In contrast to amplitude measurements, the average half-width of anti- 

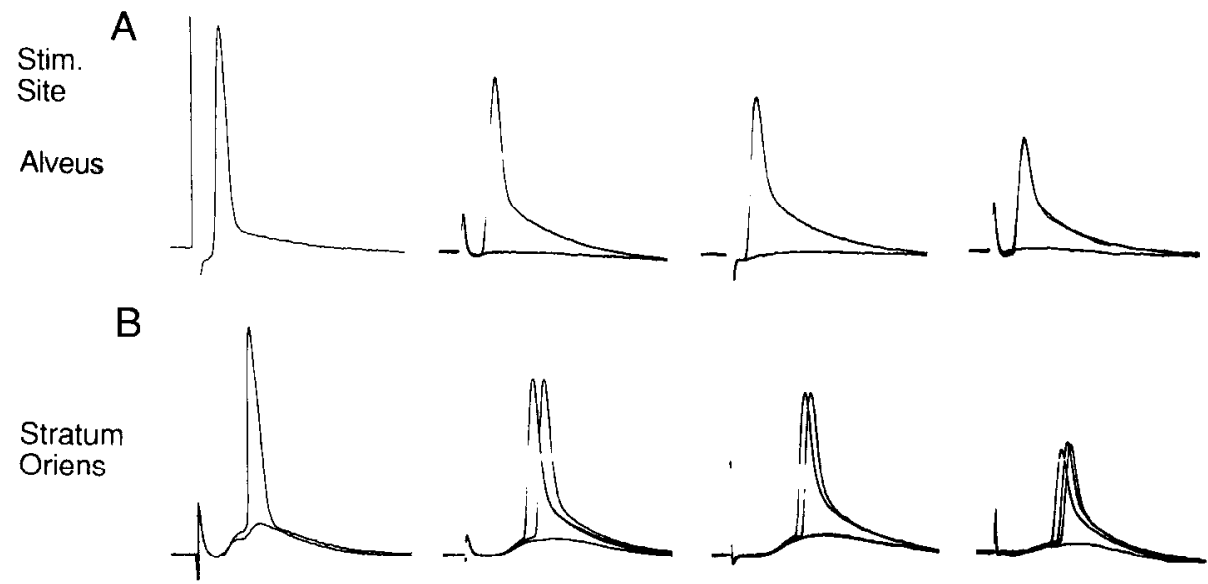

C
Stratum
Radiatum

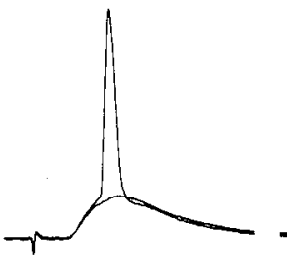

Soma

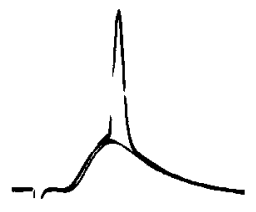

65

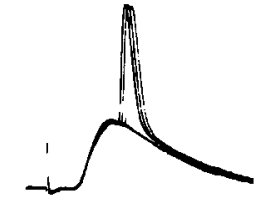

165

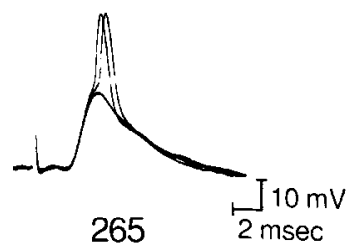

265
$2 \mathrm{msec}$
Recording Distance from St. Pyramidale $(\mu \mathrm{m})$
Figure 2. Representative examples of evoked intracellular action potential discharge recorded in pyramidal cell somata and apical dendrites at the indicated locations. $A-C$, Spike discharge was evoked by stimulation of the alveus $(A)$, stratum oriens $(B)$, or stratum radiatum $(C)$. In each case, several responses are shown superimposed for stimulus intensities near threshold for spike discharge. Antidromic and orthodromic spikes could be recorded in apical dendritic impalements up to $265 \mu \mathrm{m}$ from stratum pyramidale. The amplitude of SO- and SR-evoked EPSPs decreased along the apical dendritic axis in an opposite manner from their respective sites of origin in the basal or apical dendritic region, respectively. Note that both antidromic and orthodromic spikes also exhibit a progressive change with recording distance. Somatic recordings were taken from three separate cells, while dendritic recordings at each location are from single dendritic impalements. All recordings are displayed on a common voltage and time base for direct comparison. dromic and orthodromic spikes was shortest at the level of somata and proximal dendrites and increased with distance along the dendritic axis. In each case, the greatest change in amplitude or half-width was found at sites in the proximal $(\approx 100 \mu \mathrm{m})$ and more distal $(\approx 200 \mu \mathrm{m})$ regions of stratum radiatum (Fig. $3 A-$ $F$ ). It is important to note that plots of the average values of resting membrane potential (Fig. $3 G$ ) and input resistance (Fig. $3 \mathrm{H}$ ) available for these recordings suggest that the observed changes in spike amplitude and half-width are not due to a progressive decline in these membrane parameters.

\section{Voltage threshold of orthodromic spike discharge}

SR-evoked spike discharge was also found to differ between somatic and dendritic recording sites in terms of the absolute voltage threshold for spike generation. In somatic recordings exhibiting minimal reflection of extracellular potentials (Richardson et al., 1984; Taylor and Dudek, 1984), spikes were evoked from a consistent voltage threshold, arising from a similar level of depolarization regardless of the discharge latency (Fig. 4A). In contrast, orthodromic spikes in dendrites discharged from an inconsistent voltage threshold. This is particularly pronounced for the case in Figure $4 B$, in which spikes were evoked at two intensities of stimulation. At one SR stimulus intensity, spikes discharged at a voltage breakpoint near the peak of the EPSP (Fig. 4B, 12V). A lower stimulus intensity, however, also evoked a spike from a smaller EPSP and thus an apparently lower voltage threshold (Fig. $4 B, 9 \mathrm{~V}$ ).

We therefore examined the threshold for spike discharge over the somatodendritic axis in response to orthodromic (SO and SR) stimulation. An estimate of the voltage threshold for spike discharge was obtained by measuring the amplitude of EPSPs that did not elicit a spike when stimulus intensity was set to spike threshold ( $\approx 50 \%$ failure rate). The plots in Figure $4 C$ demonstrate that EPSP amplitude at spike threshold varied ac- cording to recording location along the dendritic axis. In the case of SR stimulation, EPSP amplitude was lowest in the somatic region, increasing through the proximal region of stratum radiatum (Fig. $4 C, 30-100 \mu \mathrm{m}$ ) to a value greater than that at the soma for recording sites $100-265 \mu \mathrm{m}$ (Fig. $4 \mathrm{C}$ ). In contrast, the amplitude of the SO-evoked EPSP at spike threshold was greatest at the soma and decreased with recording distance along the apical dendritic tree (Fig. 4C). Thus, at any given dendritic location, orthodromic spikes discharged at distinctly different values of membrane potential for the two forms of synaptic input (see also Fig. $2 B, C$ ). The only location at which the amplitudes of SO- and SR-evoked EPSPs (voltage thresholds) were equivalent was in the region of the cell body layer (Fig. $4 C, 0$ $\mu \mathrm{m})$. Plots of the average values of resting membrane potential and input resistance for these impalements (Fig. $4 D$ ) demonstrate that these parameters did not vary systematically with recording distance from stratum pyramidale.

SR-evoked spike initiation for threshold versus suprathreshold stimulation

The preceding data indicate that orthodromic SR-evoked spikes are very similar in form to a spike conducting antidromically over the apical dendritic axis (Figs. 2,3), and that only the cell body region exhibits a threshold consistent with a voltage-dependent response (Fig. 4). Each of these results is at least suggestive evidence or a site of origin for SR-evoked spike discharge at or near the somatic level. However, it has been shown that SR stimulation evokes a short-latency, negative-going field potential and current sink (putative $\mathrm{Na}^{+}$spike discharge) in the region of proximal apical dendrites (Cragg and Hamlyn, 1955; Andersen, 1960; Fujita and Sakata, 1962; Taube and Schwartzkroin, 1988b; Turner et al., 1989; Herreras, 1990). As this potential is TTX sensitive and contributes to generation of the population spike in stratum pyramidale (Taube and Schwartz- 
A

Stim. Site Alveus

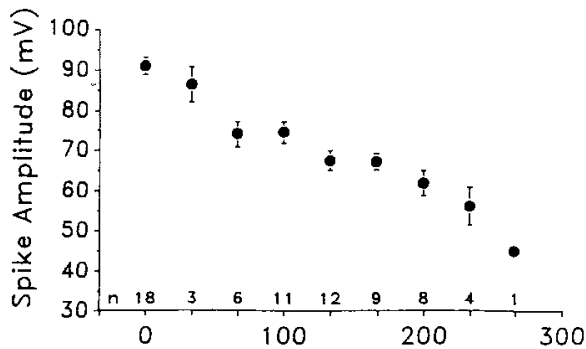

D

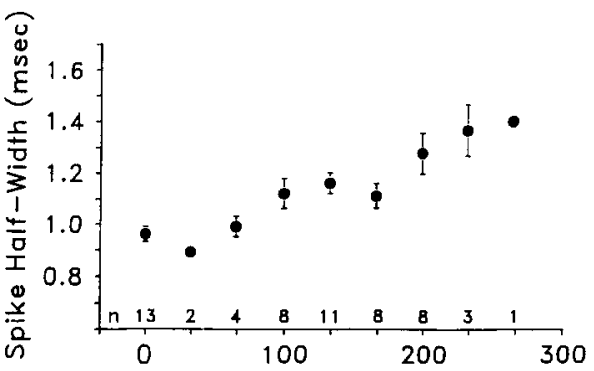

B

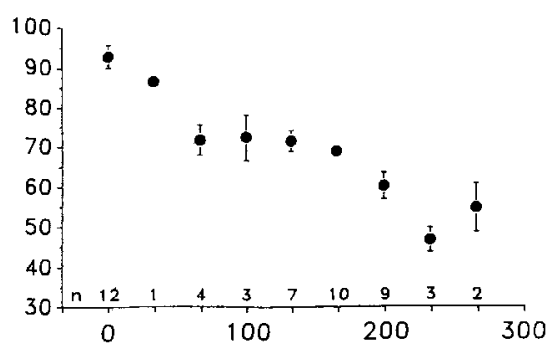

E

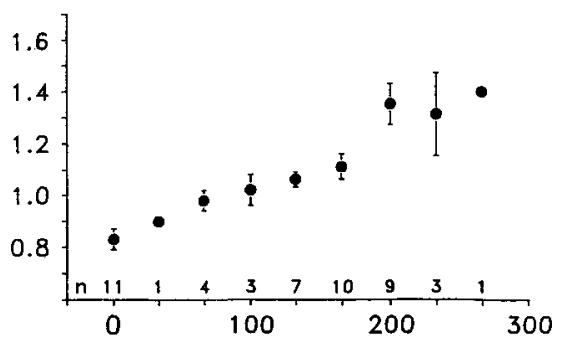

C

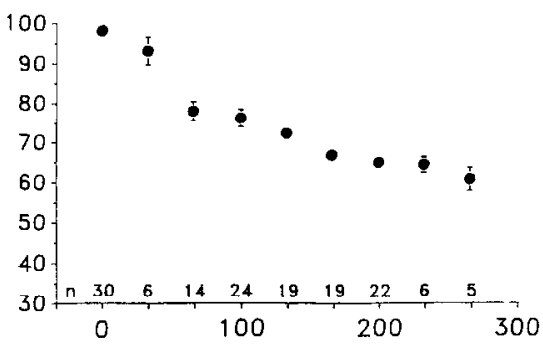

F

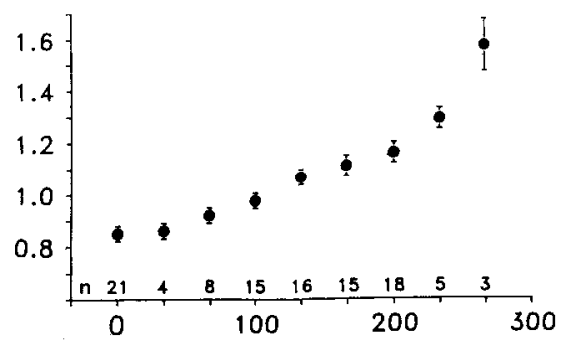

G

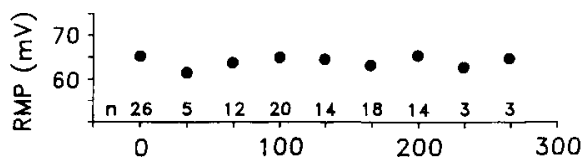

Distance from Stratum Pyramidale $(\mu \mathrm{m})$
$\mathrm{H}$

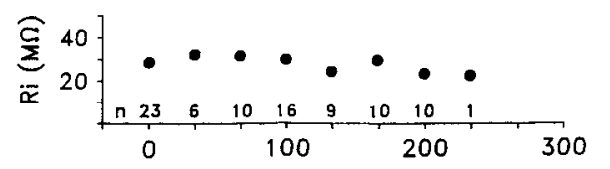

Distance from Stratum Pyramidale ( $\mu \mathrm{m})$

Figure 3. The amplitude and half-width of antidromic and orthodromic spikes change progressively with recording distance over the somatodendritic axis. Spikes were evoked by stimulation of the alveus, stratum oriens, or stratum radiatum using threshold intensities for spike discharge at each location. Recordings were obtained in pyramidal cell somata $(0 \mu \mathrm{m})$ and apical dendrites at various distances from stratum pyramidale. $A-C$. Plots of the average spike amplitude reveal a gradual decline in spike amplitude from the soma through apical dendrites for both antidromic and orthodromic forms of stimulation. $D-F$, Plots of the average spike half-width (width at half amplitude) reveal a gradual increase in the halfwidth of antidromic and orthodromic spikes with dendritic recording distance. $G$ and $H$, Plots of the average values of resting membrane potential (RMP; $G)$ and input resistance $(R i ; H)$ available at each location illustrate that these parameters do not exhibit a comparable change over the somatodendritic axis. The number of impalements $(n)$ at each location are shown above the abscissa of each graph, with measurements taken from the largest spike recorded in each impalement. Values without $S E$ bars are those in which the bars are within the boundary of the illustrated data point.

kroin, 1988b; Turner et al., 1989; Herreras, 1990), it may correspond to a subset of the cell population initiating spike discharge at the dendritic level. We therefore examined the relationship of intradendritic spikes to the proximal dendritic field potential and cell body population spike, focusing upon the effects of threshold and suprathreshold SR stimulation.

Temporal relationship between field potentials and SR-evoked intradendritic spikes

For these experiments, SR-evoked intradendritic spike discharge was recorded at threshold and suprathreshold intensity while simultaneously recording the cell body population spike in stratum pyramidale. After collecting intradendritic spike responses, the electrode was withdrawn and extradendritic field potentials evoked at the same stimulus intensities were recorded. The latency of onset of dendritic spikes was then compared to the peak latencies of population spike responses.

At threshold intensity, a total of 32 out of 41 dendritic spikes ( $n=20$ impalements) discharged with an onset latency following the peak of the cell body population spike (Fig. $5 A$, broken lines; difference of $0.6 \pm 0.1 \mathrm{msec} ; n=41$ ), while eight were not significantly different. Similarly, 40 out of 41 dendritic spikes arose following the peak of the extradendritic population response (Fig. $5 A$; difference of $1.2 \pm 0.15 \mathrm{msec} ;=41$ ). These differences were highly statistically significant $(p<0.0001$, Wilcoxon signed ranks test, double-sided probability; $n=41$ ). If the site for spike initiation was constant, one would expect a comparable shift in the latency of intra- and extracellular spike responses as stimulus intensity was increased. However, suprathreshold intensity changed the temporal relationship between spike discharge and extracellular population responses. Under these conditions the onset of intradendritic spikes in all $20 \mathrm{im}$ palements clearly preceded the peak of the cell body population spike (Fig. $5 B$; difference of $0.7 \pm 0.06 \mathrm{msec} ; p<0.001$, Wilcoxon signed ranks test, double-sided probability; $n=20$ ). Similarly, 17 out of 20 dendritic spikes discharged with an onset latency prior to the peak of the proximal dendritic population response (Fig. $5 B$; difference of $0.2 \pm 0.07 \mathrm{msec} ; p<0.005$, Wilcoxon signed ranks test, double-sided probability; $n=20$ ). Thus, at suprathreshold intensity, SR-evoked intradendritic 


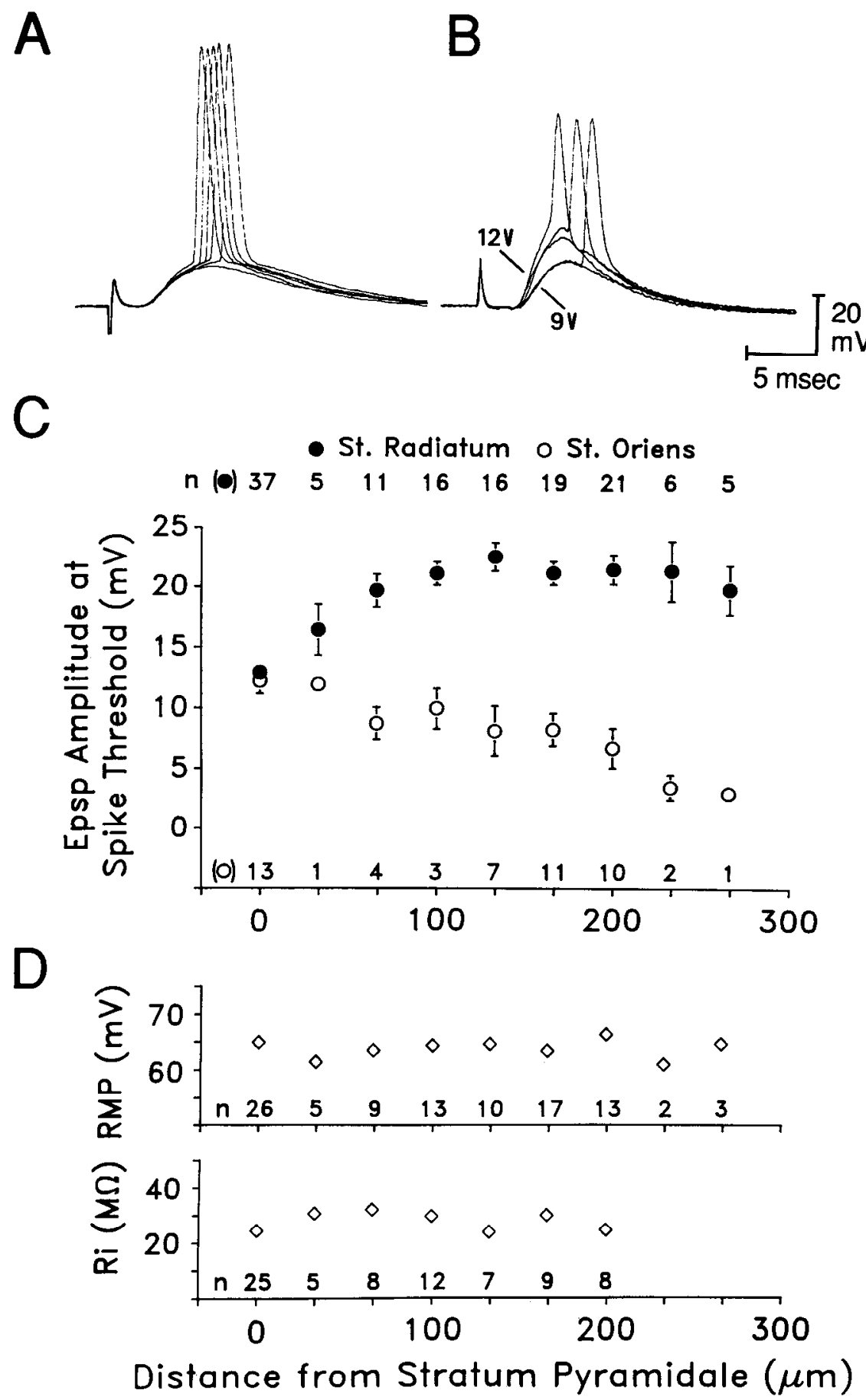

Figure 4. The amplitude of EPSPs over the dendritic axis reveals an inconsistent threshold for dendritic spike discharge. $A$ and $B$, Representative examples of SR-evoked spike discharge at the somatic $(A)$ and dendritic level $(B ; 200 \mu \mathrm{m})$ at intensities set to threshold for spike discharge (several superimposed records). Note the consistent voltage threshold for spike discharge in a somatic recording $(A)$. An inconsistent voltage threshold is observed in the apical dendrite $(B)$, with a lower stimulus intensity $(9 \mathrm{~V})$, in this case evoking a spike from a voltage level below that at a $12 \mathrm{~V}$ intensity. $C$, The amplitudes of SO- and SR-evoked EPSPs that failed to evoke a spike at threshold intensity $(\approx 50 \%$ failure rate) were used to estimate the voltage threshold for spike discharge at various locations along the somatodendritic axis (somatic recordings taken as $0 \mu \mathrm{m}$ ). Plots of the average amplitude of EPSPs reveal that spike discharge at any given dendritic location was evoked at distinctly different membrane potentials by the two forms of synaptic activation. The only location exhibiting spike discharge at a comparable membrane potential for both inputs was the cell body region. $D$, Plots of the average values of resting membrane potential $(R M P)$ and input resistance $(R i)$ available for the impalements shown in $C$. The number of impalements $(n)$ at each location are shown above the abscissa of each graph, while those for SR-evoked EPSPs (solid circles) are shown at the top of $C$. Average values without $S E$ bars are those in which the bars are within the boundary of the illustrated data point.

spikes aligned with the negative-going component of the extradendritic population potential (Fig. $5 B$ ) proposed to represent spike discharge in dendrites prior to that in the soma (Turner et al., 1989; Herreras, 1990).

\section{Dependence of intradendritic spike discharge on generation of the cell body population spike}

In order to determine the dependence of dendritic spikes upon generation of the cell body population spike (somatic spike discharge), we applied TTX locally in stratum pyramidalc while recording SR-evoked intradendritic spikes. The spread of TTX from stratum pyramidale was assessed by placing a second extracellular recording electrode in proximal stratum radiatum in order to monitor the amplitude of the TTX-sensitive proximal dendritic field potential.

When the SR stimulus intensity was set near threshold for spike discharge (Fig. 6A), TTX ejection in stratum pyramidale that reduced the cell body population spike also blocked discharge of the intradendritic spike in an all-or-none manner (Fig. $6 B ; n=4)$. In each case, the amplitude and rising phase of the proximal dendritic ficld potential was unaffected at this time, indicating that TTX was localized to stratum pyramidale (Fig. 

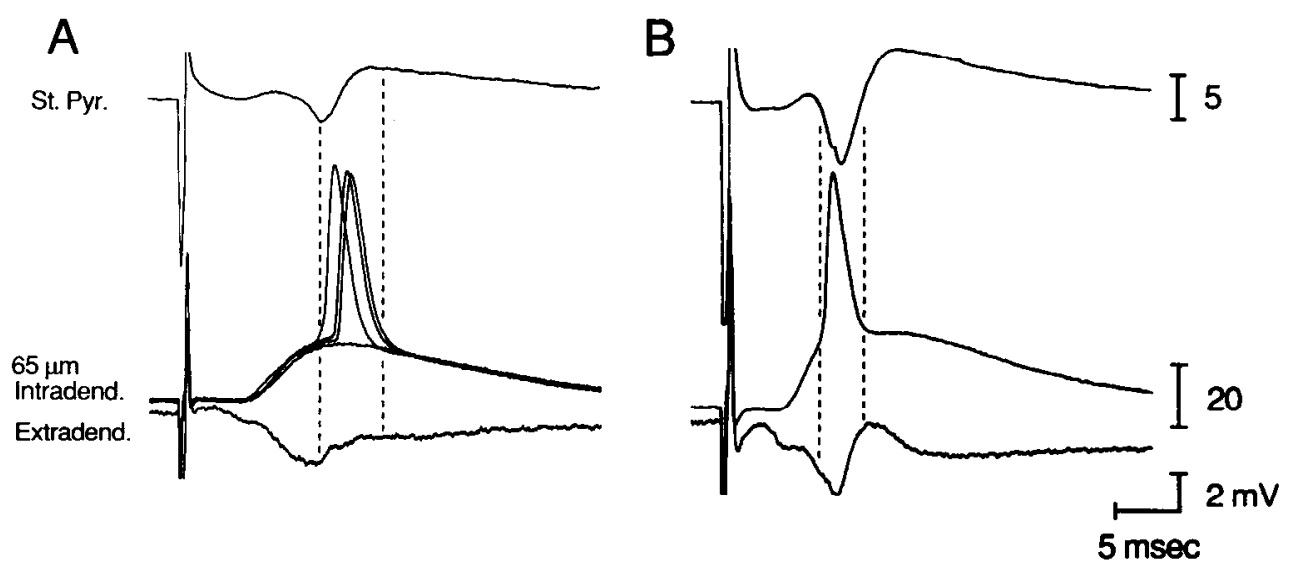

Figure 5. The temporal relationship between SR-evoked dendritic spikes and extracellular field potentials differs at threshold and suprathreshold stimulus intensities. Shown in $A$ and $B$ are the population responses recorded in stratum pyramidale (St. Pyr.), the intradendritic potential (Intradend.), and the extradendritic field potential (Extradend.) recorded after withdrawal of the intradendritic electrode. Broken lines are drawn at the approximate onset and termination of intradendritic spike discharge. $A$, At intensities near threshold for spike discharge (several sweeps superimposed), intradendritic spikes were evoked with a latency to onset following the peak of both the cell body population spike in stratum pyramidale and the short-duration population discharge in proximal stratum radiatum. $B$, At higher intensities, intradendritic spikes discharged with a shorter latency to onset than the peak of the cell body population spike and the peak of the negative-going population response of the proximal dendritic field potential. Extracellular recordings are averages of three responses.

6B). Discharge of dendritic spikes remained blocked for several minutes following the introduction of TTX into stratum pyramidale, but returned following a partial or complete recovery of the cell body population spike. Unexpectedly, we found that spike discharge was restored shortly after blockade by TTX if the stimulus intensity was increased (Fig. $6 C ; n=3$ ), suggesting more than one site for initiation of spike discharge (i.e., dendritic).

The results from a similar experiment in which intradendritic spikes were evoked from the outset at an intensity of approximately twice threshold are shown in Figure $6 D-F(n=8)$. At suprathreshold intensity, repetitive ejections of TTX (five or six pulses) in stratum pyramidale that completely blocked the cell body population spike and reduced the proximal dendritic field potential had little effect on the intradendritic spike (Fig. $6 E$ ). Additional ejections of TTX were then used to promote diffusion of TTX farther into the apical dendritic region. This action eventually blocked the dendritic spike (Fig. $6 F$ ), but not in the all-or-none manner observed at threshold intensity. Instead, the rate of rise and amplitude of the dendritic spike decreased in a "graded" manner until only the underlying EPSP remained (seven of eight dendrites; Fig. $6 F$ ). In one impalement, complete spike failure was preceded by the recording of an FPP of $11 \mathrm{mV}$ that subsequently failed to the EPSP. It is important to stress that the decrease in dendritic spike amplitude was closely associated with a decrease in the amplitude of the proximal dendritic field potential. Indeed, final blockade of the intradendritic spike coincided with the complete loss of the short-duration proximal dendritic field potential negativity (Fig. $6 F ; 50 \mu \mathrm{m}$ ). However, for each case of suprathreshold stimulation, the rate of rise of the synaptic potential was unchanged at the time of spike blockade (Fig. $6 F ; 130 \mu \mathrm{m}$ ), demonstrating that TTX had not diffused to the region of activated afferent fibers in distal stratum radiatum to affect the strength of synaptic drive.

\section{SR-evoked spike parameters at suprathreshold stimulus intensity}

The preceding data indicate that blockade of dendritic spikes evoked at suprathreshold stimulus intensity required that TTX act at a site within the dendritic arborization. Therefore, we reexamined SR-evoked spikes over the somatodendritic axis for any change in amplitude or half-width that might signify a shift in spike initiation to dendritic membrane at suprathreshold intensities (Fig. 7). Plots of the average amplitude (Fig. 7A) and half-width (Fig. $7 B$ ) of SR-evoked spikes illustrate that these parameters underwent a similar change with recording distance from stratum pyramidale irrespective of stimulus intensity.

Measurements of SR-evoked spike threshold at suprathreshold intensity were not feasible given the difficulty in defining the onset of action potential discharge from the rising edge of the EPSP. Nevertheless, an estimate of spike threshold at high intensity may be gained from the amplitude of the dendritic EPSP uncovered after TTX had diffused from the cell body layer and into stratum radiatum to block the dendritic spike (see Fig. $6 F ; 130 \mu \mathrm{m}$ ). The amplitude of dendritic EPSPs uncovered in this manner ranged between 28 and $39 \mathrm{mV}$ for recordings between 65 and $200 \mu \mathrm{m}(32 \pm 1.6 \mathrm{mV} ; n=8)$. As evident in Figure $6 F$, these EPSPs were not greatly above threshold for discharge in these locations, as the spike failed near the peak of the synaptic response.

\section{Discussion}

The concept that orthodromic depolarization can result in spike discharge in pyramidal cell dendrites has come from several extracellular field potential (Cragg and Hamlyn, 1955; Andersen, 1959, 1960; Fujita and Sakata, 1962; Miyakawa and Kato, 1986; Richardson et al., 1987; Turner et al., 1989; Herreras, 1990) and intradendritic analyses (Wong and Prince, 1979; Wong et al., 1979; Masukawa and Prince, 1984; Taube and Schwartzkroin, 1988a). Our work confirms and extends this by establishing the intracellular distribution, characteristics, and site of origin of spike discharge in CA1 pyramidal cells.

As reported previously (Wong et al., 1979; Masukawa and Prince, 1984; Taube and Schwartzkroin, 1988a), orthodromic stimulation evoked single, short-duration spikes of constant amplitude under normal recording conditions. Thus, antidromic and orthodromic spikes contrast sharply with the variable-amplitude, long-duration $\left(\mathrm{Ca}^{2+}\right.$-dependent) potentials evoked in the 

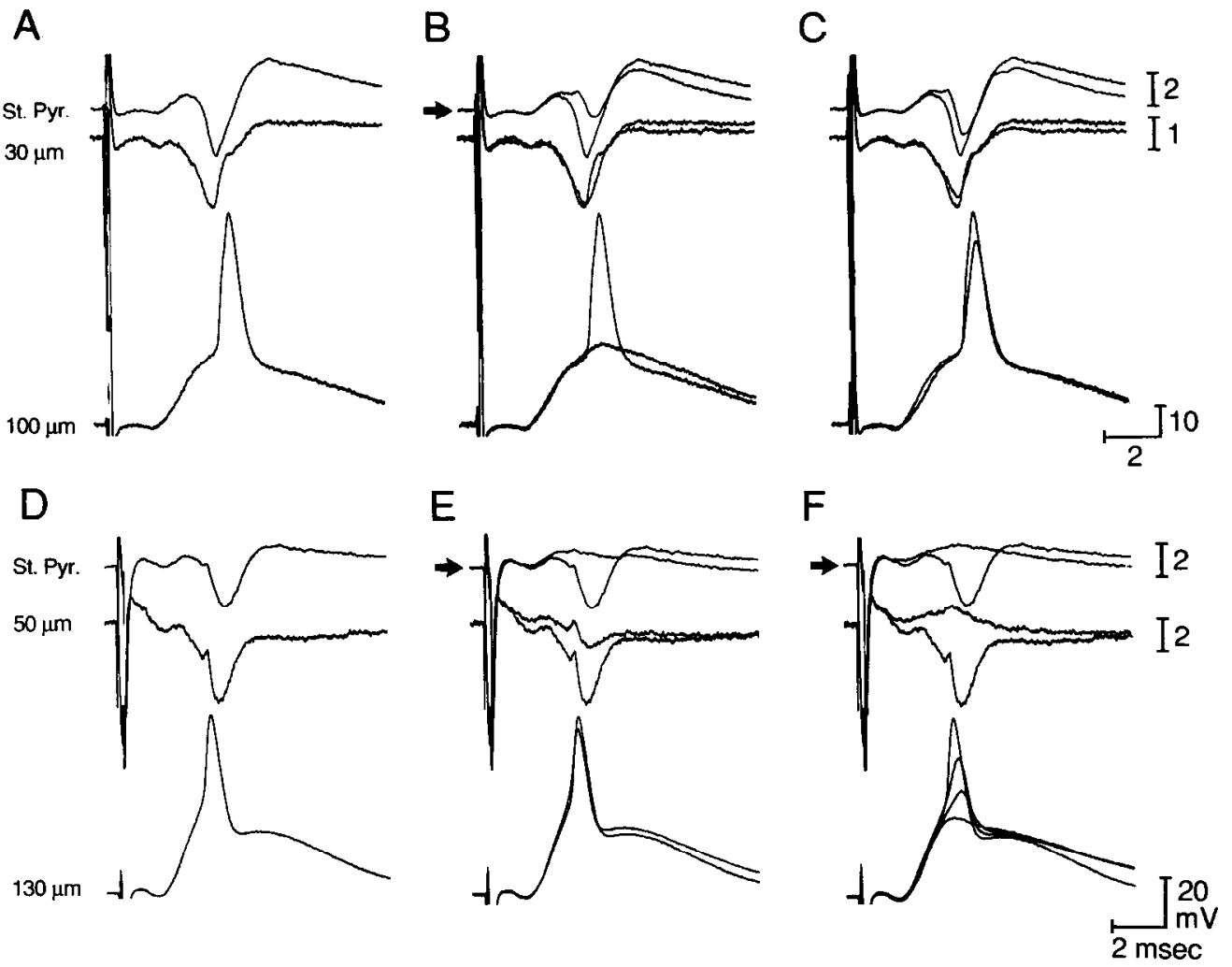

Figure 6. Orthodromic stimulus intensity determines the site of origin for spike discharge. In each panel, the two upper records are extracellular population responses recorded at the sites indicated, and the lower record illustrates the intradendritic spike. The SR stimulus was set to threshold $(A-C)$ or suprathreshold $(D-F)$ intensity for intradendritic spike discharge. Arrows indicate the site and times at which TTX (20 $\mu \mathrm{M})$ was ejected from the extracellular recording clectrode located in stratum pyramidale. Control responses $(A$ and $D)$ are shown superimposed on responses recorded immediately following TTX ejections. $A-C$, The intradendritic spike recorded at threshold stimulus intensity $(A)$ failed in an all-or-none manner $(B)$ when TTX ejection in stratum pyramidale reduced the amplitude of the cell body population spike. $C$, The dendritic spike response reappeared in nearly complete form when the stimulus intensity was increased. $D-F$, In contrast, an intradendritic spike evoked at suprathreshold intensity $(D)$ was virtually unaffected by several applications of TTX that abolished the cell body population spike ( $E$; six pulses). The reduction in the amplitude of the proximal dendritic field potential $(E ; 50 \mu \mathrm{m})$ indicates that TTX had diffused into proximal stratum radiatum at this time. Continued ejections of TTX completely blocked the proximal dendritic field potential $(F ; 50 \mu \mathrm{m} ; 10$ pulses; last response shown) and simultaneously decreased the amplitude of the dendritic spike until only the underlying EPSP remained $(F ; 130 \mu \mathrm{m}$; several records superimposed). Extracellular recordings are averages of three responses. The small deflection on the superimposed records in $B(30 \mu \mathrm{m})$ is the result of capacitive coupling between the intradendritic and proximal dendritic recording electrode during spike discharge.

presence of epileptiform agents or by depolarizing current pulses (Wong and Prince, 1979; Benardo et al., 1982; Masukawa and Prince, 1984). Rather, the sensitivity of evoked spikes to local TTX application (Fig. 6; Miyakawa and Kato, 1986; Turner et al., 1989) demonstrate that $\mathrm{Na}^{+}$ions are the principle charge carrier for antidromic and orthodromic action-potential discharge in both somatic and apical dendritic locations.

\section{Intradendritic recordings}

A prominent aspect of dendritic recordings is the extent to which both EPSPs and spikes exhibit a progressive change in waveform with recording distance from stratum pyramidale (Figs. 2-4). Several characteristics of our recordings indicate that these changes are not due to membrane damage associated with impalement by a microelectrode. Membrane potential recovered quickly to rest after initial impalement $(<1-2 \mathrm{~min})$ with little variation in resting potential or input resistance over time $(\leq 3$ $\mathrm{hr}$ ). Potentials recorded from specific levels of the dendritic axis were also very consistent from one slice to the next, as indicated by the small SEs associated with EPSP and spike measurements (Figs. 3, 4). Finally, input resistance did not change over the somatodendritic axis in a manner suggesting a progressive loss of membrane resistance (Figs. $3 H, 4 D$ ).

The similarity of input resistance in somatic and dendritic locations was not intuitively expected given the difference in diameter of pyramidal cell somata $(10-15 \mu \mathrm{m})$ and apical dendrites (1-4 $\mu \mathrm{m}$; Westrum and Blackstad, 1962). A proportional decline in the quality of impalements and membrane sealing in dendritic recordings might be offered as one explanation for this result. However, considering that pyramidal cells exhibit an average electrotonic length $(L)$ of $<1.0$ (Turner and Schwartzkroin, 1980; Brown et al., 1981), a more likely explanation is that our dendritic recording sites were electrotonically close to the cell body region. Given that the majority of our impalements probably correspond to the larger dendritic processes, a similar value for somatic and dendritic input resistance may in fact be expected. The steady state voltage achieved by current injection is thus similar at both the somatic and the dendritic level as current will source over a comparable area of membrane (as discussed by Rall, 1981). Finally, measured values of input resistance may also reflect the distribution of conductances (intrinsic or synaptic) active near resting potential in somatic versus 

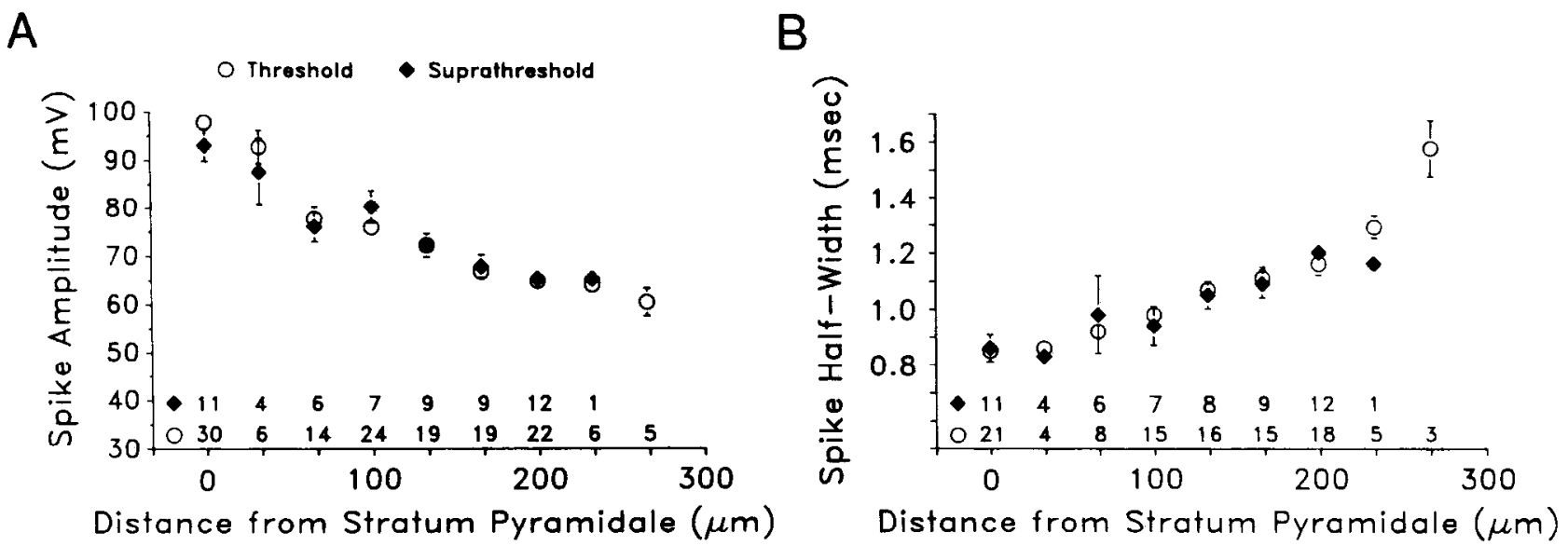

Figure 7. Comparison of orthodromic spike amplitude and half-width at various locations over the cell axis for threshold and suprathreshold SR stimulus intensities. $A$ and $B$, Plots of the average amplitude $(A)$ and half-width $(B)$ of SR-evoked spikes recorded at various locations and evoked at either threshold (circles) or suprathreshold intensity (diamonds). Somatic recordings are taken as $0 \mu \mathrm{m}$. Note the similarity in the change in amplitude and half-width of spikes over the dendritic axis for both stimulus intensities. The number of impalements at each site are shown above the abscissa of each graph. Average values without $S E$ bars are those in which the bars fall within the boundary of the illustrated data point.

dendritic membrane (Madison et al., 1986; Storm and Helliesen, 1989). Therefore, both the change in shape of evoked potentials and the similarity of input resistance over the cell axis reported here are considered to reflect the physiological activity of CA1 pyramidal cells.

\section{Site for initiation of action potential discharge}

Previous field potential studies have established that alvear and SO stimulation evokes a short-latency spike discharge in the cell body region that subsequently conducts in a retrograde fashion through stratum radiatum (Sperti et al., 1967; Leung, 1979; Miyakawa and Kato, 1986; Richardson et al., 1987; Turner et al., 1989). According to a scheme tentatively proposed by Spencer and Kandel (1961), orthodromic depolarizations may initiate spike discharge at the dendritic level at restricted sites exhibiting a low threshold for spike generation ("hot spots").

Our attempts at measuring orthodromic spike threshold reveal that at any given dendritic location, orthodromic spikes discharged from an inconsistent level of membrane potential. This was particularly evident in the different amplitudes of SRand SO-evoked EPSPs underlying spike discharge at threshold intensity (Fig. 4C). This differs from the expected result, as voltage-dependent spike discharge should arise from a consistent voltage level at the location of lowest threshold. Indeed, a strict interpretation of the results in Figure $4 C$ implies that (1) spike discharge in apical dendrites is most effectively evoked by an EPSP of basal dendritic origin, and (2) a spike at any given dendritic location can be evoked at two distinct voltage thresholds (see also Fig. $2 B, C$ ). The simplest interpretation of these results is that an intradendritic recording electrode is distant to the initial site for spike generation. It is entirely possible that dendritic hot spots of low threshold were present at sites remote to the dendritic impalements obtained. However, the only location at which orthodromic spikes were evoked at a constant threshold was the cell body layer (Fig. 4A,C).

The above data are consistent with the interpretation that orthodromic spike discharge is initiated in the cell body region at threshold intensity, followed by a retrograde spike invasion of dendritic membrane. The amplitude of SR- and SO-evoked EPSPs at threshold intensity then simply reflects the local am- plitude of EPSPs conducting from their respective dendritic origins in the course of raising the cell body region to spike threshold. This accounts for the inconsistent threshold measurements, as an action potential conducting into the apical dendrites will superimpose upon the coincident level of depolarization within a particular dendritic branch. Direct support for a somatic site of origin for spike discharge was in fact obtained when TTX applications in stratum pyramidale blocked generation of the SR-evoked dendritic spike (Fig. 6A.B). Thus, action potential generation at threshold intensity is dependent upon TTX-sensitive conductances in or very near the cell body region (Lanthorn et al., 1984; French and Gage, 1985; MacVicar, 1985; Andersen, 1986; Miyakawa and Kato, 1986; Turncr ct al., 1989).

The TTX experiments were also critical in revealing that the site for initiation of SR-evoked spike discharge depends upon the intensity of orthodromic activation. SR-evoked spikes at suprathreshold intensity were blocked only when TTX had diffused into stratum radiatum (Fig. $6 D-F$ ), suggesting a shift in the site of origin for spike discharge into the apical dendritic region. This was further supported by the disproportionate shift in latency of intradendritic versus population spikes when stimulus intensity was increased beyond spike threshold (Fig. 5). Although the maximal distance over which the site of origin can shift has not been determined, our most distal recording for the TTX experiments was at $216 \mu \mathrm{m}$, indicating a shift of at least this distance from stratum pyramidale. It is important to note that suprathreshold intensities used in the present study correspond to those necessary to evoke $\geq 3-4 \mathrm{mV}$ cell body population spike. These are not particularly high intensities, as the maximal cell body population spike evoked in the CAl region can attain values in the range of $15-25 \mathrm{mV}$.

The simplest explanation for our results is that the lowest threshold for spike discharge is located in the cell body region and that depolarizations straddling threshold first evoke spike discharge at this location. As determined by the results shown in Figure 4, an unequivocal measure of the threshold for initiating a spike at the dendritic level cannot be obtained by simple membrane depolarization (i.e., current injection), because a spike can arise from the somatic region. One needs to measure spike 
threshold under conditions known to initiate spike discharge in the vicinity of a dendritic recording electrode, as now shown for the case of suprathreshold SR stimulation. Therefore, the only available estimate of the threshold for initiating a dendritic spike is the amplitude of the EPSP remaining after TTX had blocked the dendritic spike at this intensity (see Fig. 6F). Notwithstanding possible TTX effects on slow prepotentials or the more distant afferent fibers, the EPSPs uncovered in this manner had an average amplitude of $32 \pm 1.6 \mathrm{mV}(n=8)$. This compares to $12.9 \pm 0.7 \mathrm{mV}(n=37)$ for somatic EPSP amplitudes near threshold for spike discharge (Fig. 4C). Taken together, these data suggest that spike threshold is higher in dendritic than in somatic membrane, and that initiation of spike discharge in dendrites requires a greater level of orthodromic depolarization.

Factors contributing to spike conduction over the dendritic axis

The similarity of anti- and orthodromic spike amplitudes and half-widths over the dendritic axis at threshold intensity might be accounted for by a common somatic site for initiation and subsequent conduction through apical dendrites. However, a comparison of SR-evoked spikes at threshold and suprathreshold intensity demonstrates that these parameters are determined by factors independent of the site for spike initiation. This can be readily accounted for if SR-evoked spikes conduct actively over the dendritic axis, as shown by their TTX sensitivity (Fig. 6D-F; Miyakawa and Kato, 1986; Turner et al., 1989). Local dendritic factors such as the density of $\mathrm{Na}^{+}$channels or branch diameter are then more likely determinants of the orthodromic spike waveform. Binding of labeled TTX (Mourre et al., 1988) and $\mathrm{Na}^{+}$-channel immunoreactivity has been reported in stratum radiatum of CAl (Westenbroek et al., 1989), but the density and distribution of this labeling at the single cell level is unknown. We are therefore unable to identify or speculate on the distribution pattern of $\mathrm{Na}^{+}$channels (punctate vs. diffuse) that support the initiation or conduction of a spike in dendritic locations at this time.

The results of this and a previous investigation (Turner et al., 1989) demonstrate that the site for spike initiation in CAl pyramidal cells is extremely labile and can shift between somatic and dendritic locations depending upon the conditions of orthodromic depolarization. This has important implications, as the probability of spike discharge at the axon hillock will exhibit a nonlinear relationship to the intensity of synaptic input. A somatodendritic shift in spike generation may then underlie certain forms of synaptic plasticity, particularly those identified as "extrasynaptic" contributions to paired-pulse potentiation (Low et al., 1983) and long-term ("E-S") potentiation (Andersen et al., 1980; Abraham et al., 1985; Taube and Schwartzkroin, 1988a,b).

\section{References}

Abraham WC, Bliss TVP, Goddard GV (1985) Heterosynaptic changes accompanying long-term but not short-term potentiation of the perforant path in the anesthetized rat. J Physiol (Lond) 363:335-349.

Andersen P (1959) Interhippocampal impulses. I. Origin, course and distribution in cat, rabbit and rat. Acta Physiol Scand 47:63-90

Andersen P (1960) Interhippocampal impulses. II. Apical dendritic activation of CAl neurons. Acta Physiol Scand 48:178-208.

Andersen P (1986) Factors influencing the efficiency of dendritic synapses on hippocampal pyramidal cells. Neurosci Res 3:521-530.

Andersen P, Lomo T (1966) Mode of activation of hippocampal pyramidal cells by excitatory synapses on dendrites. Exp Brain Res 2: $247-260$.
Andersen P, Sundberg SH, Sveen O, Swann JW, Wigstrom H (1980) Possible mechanisms for long-lasting potentiation of synaptic transmission in hippocampal slices from guinea-pig. J Physiol (Lond) 302 $463-482$

Ashwood TJ, Lancaster B, Wheal HV (1984) In vivo and in vitro studies on interneurons in the rat hippocampus: possible mediators of feedforward inhibition. Brain Res 293:279-291.

Benardo LS, Masukawa LM, Prince DA (1982) Electrophysiology of isolated hippocampal dendrites. J Neurosci 2:1614-1622.

Brown TH, Fricke RA, Perkel DH (1981) Passive electrical constants in three classes of hippocampal neurons. J Neurophysiol 46:812-827.

Coombs JS, Curtis DR, Eccles JC (1957) The interpretation of spike potentials of motoneurons. J Physiol (Lond) 139:198-231.

Cragg BG, Hamlyn LH (1955) Action potentials of the pyramidal neurons in the hippocampus of the rabbit. J Physiol (Lond) 129:608627.

Faber DS, Korn H (1986) Instantaneous inward rectification in the Mauthner cell: a postsynaptic booster for excitatory inputs. Neuroscience 19:1037-1043.

French CR, Gage PW (1985) A threshold sodium current in pyramidal cells in rat hippocampus. Neurosci Lett 56:289-293.

Fujita Y, Sakata H (1962) Electrical properties of CA1 and CA2 apical dendrites of rabbit hippocampus. J Neurophysiol 25:209-222.

Funch PG, Faber DS (1982) Action potential propagation and orthodromic impulse initiation in Mauthner axon. J Neurophysiol 47: 1214-1231.

Herreras O (1990) Propagating dendritic action potential mediates synaptic transmission in CA1 pyramidal cells in situ. J Neurophysiol 64:1429-1441.

Huguenard JR, Hamill OP, Prince DA (1989) Sodium channels in dendrites of rat cortical pyramidal neurons. Proc Natl Acad Sci USA 86:2473-2477.

Jeffereys JGR (1979) Initiation and spread of action potentials in granule cells maintained in vitro in slices of guinea-pig hippocampus J Physiol (Lond) 289:375-388.

Lacaille J-C, Schwartzkroin PA (1988a) Stratum lacunosum-moleculare interneurons of hippocampal CAl region. I. Intracellular response charactcristics, synaptic responses, and morphology. J Neurosci 8:1400-1410.

Lacaille J-C, Schwartzkroin PA (1988b) Stratum lacunosum-moleculare interneurons of hippocampal CA1 region. II. Intrasomatic and intradendritic recordings of local circuit synaptic interactions. J Neurosci 8:1411-1424.

Lanthorn T, Storm J, Andersen P (1984) Current-to-frequency transduction in CA1 hippocampal pyramidal cells: slow pre-potentials dominate the primary range firing. Exp Brain Res 53:431-443.

Leung LS (1979) Potentials evoked by alvear tract in hippocampal CA1 region of rats. II. Spatial field analysis. J Neurophysiol 42:15711589 .

Llinas R, Sugimori M (1980) Electrophysiological properties of in vitro Purkinje cell dendrites in mammalian cerebellar slices. J Physiol (Lond) 305:197-213.

Low WC, Bement SL, Whitehorn D (1983) Field potential evidence for extrasynaptic alterations in the hippocampal CAl pyramidal cell population during paired pulse potentiation. Exp Neurol 80:9-22.

MacVicar BA (1985) Depolarizing prepotentials are $\mathrm{Na}^{+}$dependent in CA1 pyramidal neurons. Brain Res 333:378-381.

MacVicar BA, Dudek FE (1981) Electrotonic coupling between pyramidal cells: a direct demonstration in rat hippocampal slices. Science 213:782-785.

Madison DV, Malenka RC, Nicoll RA (1986) Phorbol esters block a voltage-sensitive chloride current in hippocampal pyramidal cells. Nature 321:695-698.

Masukawa LM, Prince DA (1984) Synaptic control of excitability in isolated dendrites of hippocampal neurons. J Neurosci 4:217-227.

Miles R, Wong RKS (1986) Excitatory synaptic interactions between CA3 neurons in the guinea-pig hippocampus. J Physiol (Lond) 373: $397-418$.

Miyakawa H, Kato H (1986) Active properties of dendritic membrane examined by current source-density analysis in hippocampal CA1 pyramidal neurons. Brain Res 399:303-309.

Mourre C, Moll C, Lombet A, Lozdunski M (1988) Distribution of voltage-dependent $\mathrm{Na}^{+}$channels by high-affinity receptors for tetrodotoxin and saxitoxin in rat and human brains: quantitative autoradiographic analysis. Brain Res 448:128-139. 
Rall W (1981) Functional aspects of neuronal geometry. In: Neurones without impulses (Roberts A, Bush BMH, eds), pp 223-254. Cambridge: Cambridge UP.

Richardson TL, Turner RW, Miller JJ (1984) Extracellular fields influence transmembrane potentials and synchronization of hippocampal neuronal activity. Brain Res 294:255-262.

Richardson TL, Turner RW, Miller JJ (1987) Action potential discharge in hippocampal CA1 pyramidal neurons: current source-density analysis. J Neurophysiol 58:981-996.

Schwartzkroin PA, Mathers LH (1978) Physiological and morphological identification of a nonpyramidal hippocampal cell type. Brain Res 157:1-10.

Schwartzkroin PA, Prince DA (1980) Changes in excitatory and inhibitory synaptic potentials leading to epileptiform activity. Brain Res 183:61-76

Spencer WA, Kandel ER (1961) Electrophysiology of hippocampal neurons. IV. Fast pre-potentials. J Neurophysiol 24:272-285.

Sperti L, Gessi T, Volta F (1967) Extracellular potential field of antidromically activated CA1 pyramidal neurons. Brain Res 3:343-361.

Storm JF, Helliesen M (1989) Evidence that a barium-sensitive current contributes to the resting potential and spike repolarization in rat hippocampal neurons. Soc Neurosci Abstr 15:77.

Swann JW, Brady RJ, Friedman RJ, Smith EJ (1986) The dendritic origins of penicillin-induced epileptogenesis in CA 1 hippocampal pyramidal cells. J Neurophysiol 56:1718-1738.

Taube JS, Schwartzkroin PA (1988a) Mechanisms of long-term potentiation: EPSP/spike dissociation, intradendritic recordings, and glutamate sensitivity. J Neurosci 8:1632-1644.

Taube JS, Schwartzkroin PA (1988b) Mechanisms of long-term potentiation: a current source-density analysis. J Neurosci 8:1645-1655.

Tauc $L$ (1962) Identification of active membrane areas in the giant neuron of Aplysia. J Gen Physiol 45:1099-1115.
Taylor CP, Dudek FE (1984) Excitation of hippocampal pyramidal cells by an electrical field effect. J Neurophysiol 52:126-142.

Turner DA, Schwartzkroin PA (1980) Steady-state electrotonic analysis of intracellularly stained hippocampal neurons. J Neurophysiol 44:184-199.

Turner RW, Richardson TL (1991) Apical dendritic depolarizations and field interactions evoked by stimulation of afferent inputs to rat hippocampal CAl pyramidal cells. Neuroscience 42:125-136.

Turner RW, Richardson TL, Miller JJ (1987) Site of origin of action potential discharge in hippocampal pyramidal cells. FASEB Abstr 46 342.

Turner RW, Meyers DER, Barker JL (1988) Intensity-dependent shift in the site of origin of orthodromic action potential discharge in CA1 hippocampal pyramidal neurons. Soc Neurosci Abstr 14:836.

Turner RW, Meyers DER, Barker JL (1989) Localization of tetrodotoxin-sensitive field potentials of CAl pyramidal cells in the rat hippocampus. J Neurophysiol 62:1375-1387.

Westenbroek RE, Merrick DK, Catterall WA (1989) Differential sub cellular localization of the $R_{I}$ and $R_{I I} \mathrm{Na}^{+}$channel subtypes in central neurons. Neuron 3:695-704

Westrum LE, Blackstad TW (1962) An electron microscopic study of the stratum radiatum of the rat hippocampus (regio superior, $\mathrm{CAl}$ ) with particular emphasis on synaptology. J Comp Neurol 119:281309.

Wollner DA, Catterall WA (1986) Localization of sodium channels in axon hillocks and initial segments of retinal ganglion cells. Proc Natl Acad Sci USA 83:8424-8428.

Wong RKS, Prince DA (1979) Dendritic mechanisms underlying penicillin-induced epileptiform activity. Science 204:1228-1231.

Wong RKS, Prince DA, Basbaum AI (1979) Intradendritic recordings from hippocampal neurons. Proc Natl Acad Sci USA 76:986-990. 